\title{
Time to pregnancy among the wives of men exposed to organic solvents
}

Markku Sallmén, Marja-Liisa Lindbohm, Ahti Anttila, Pentti Kyyrönen, Helena Taskinen, Erkki Nykyri, Kari Hemminki

\begin{abstract}
Objectives-To assess whether paternal exposure to organic solvents is associated with decreased fertility.

Methods-A retrospective time to pregnancy study was conducted among men biologically monitored for organic solvents. The workers were classified into exposure categories on the basis of work description and the use of solvents as reported in the questionnaires, and on biological exposure measurements. The relative fecundability density ratios (FDR-an analogue of incidence density ratio of clinically recognised pregnancies) were calculated with discrete proportional hazards regression.

Results-After three mailings 316 (72.1\%) wives of the monitored men participated. The final study population consisted of 282 couples who did not use contraception at the beginning of pregnancy. The FDRs, adjusted for potential confounders, were 0.80 (95\% confidence interval (95\% CI) 0.57 to 1.11 ) and $0.74(95 \%$ CI 0.51 to 1.06$)$ for high or frequent and low or intermediate exposure, respectively. High or frequent and low or intermediate exposure were related to decreased fecundability among primigravida (FDRs 0.36 ; 95\% CI 0.19 to 0.66 and 0.53 ; $95 \%$ CI 0.27 to 1.04 ) but not among couples with at least one previous pregnancy (FDRs $0.96 ; 95 \%$ CI 0.62 to 1.49 and 0.77 ; $95 \%$ CI 0.47 to 1.24 ). Conclusions-The findings of the study provide limited support for the hypothesis that paternal exposure to organic solvents might be associated with decreased fertility. Further studies with careful design are warranted.
\end{abstract}

(Occup Environ Med 1998;55:24-30)

Keywords: fecundability; paternal exposure; solvents; reproductive hazards

In animal tests, exposure to $\mathrm{n}$-hexane ${ }^{1}$ and thinners, particularly the components ethyl acetate and xylene, ${ }^{2}$ have caused testicular damage. Exposure to carbon disulphide ${ }^{3}$ and ethylene glycol ethers and their acetates ${ }^{4}$ have been associated with adverse effects on human sperm. Some studies suggest an association between paternal occupational exposure to solvents and adverse pregnancy outcome. ${ }^{5}$

Time to pregnancy - that is, the number of menstrual cycles women required to become pregnant-can be used as a measure of fertility. ${ }^{6}$ An increase in the time to pregnancy may indicate reproductive loss at any of several reproductive stages. These include gametogenesis, transport of germ cells, fertilisation, transport of the embryo, and early survival of the foetus. The main advantage of assessing fertility through time to pregnancy is the sensitivity to observe an effect. The disadvantages include susceptibility to selection bias and the need for data on several potential confounders. ${ }^{6}$ Valid data on time to pregnancy at a group level can be derived retrospectively, with a duration of 14 years or more. ${ }^{7}$

Two epidemiological studies on the effects of organic solvents on fecundability had nonsignificant associations. Wives of the men exposed to perchloroethylene in the drycleaning industry ${ }^{8}$ and ethylene glycol ethers in semiconductor manufacturing ${ }^{9}$ had slightly prolonged times to pregnancy.

The aim of this study was to investigate whether paternal exposure to organic solvents is associated with delayed conception. The study is an extension of that on spontaneous abortion and congenital malformation by Taskinen et $a l,{ }^{10}$ in which an association between paternal exposure to solvents and increased risk of spontaneous abortion was found.

\section{Materials and methods}

STUDY SUBJECTS

Time to pregnancy was studied among the wives of men biologically monitored for exposure to organic solvents (trichloroethylene, tetrachloroethylene, 1,1,1-trichloroethane, styrene, xylene, and toluene) at the Finnish Institute of Occupational Health (FIOH) in 1965-83. The Finnish legislation on occupational health requires regular health examinations of workers exposed to agents hazardous to health, and biological monitoring is a part of examination of workers regularly exposed to organic solvents. The biological monitoring is done as a service activity at $\mathrm{FIOH}$, and the laboratories repeatedly test for quality control. Information about the wives of the monitored men was obtained from the central population register. Only men in their first marriage at the time of the first inquiry (1985) were selected. The pregnancies $(n=2687)$ of the wives $(n=1667)$ were identified from the nationwide database on medically diagnosed pregnancies, treated in hospital between 1973 to $1983,{ }^{11}$ and from the Finnish register of congenital malformations.

In the study on pregnancy outcome, every woman with a spontaneous abortion or malformed child in the data base of pregnancies was 
defined as a case..$^{10}$ If the woman had two or more adverse pregnancy outcomes, only one was randomly selected. Women eligible as controls were those who had given birth, and had neither a registered spontaneous abortion nor a registered malformed child. If the woman had more than one birth, one pregnancy was selected randomly. Three and five age matched controls (age at the time of conception for study pregnancy) were selected for each case in the abortion and malformation studies, respectively.

This study on fertility was restricted to those cases of spontaneous abortion $(n=110)$ and controls $(n=332)$ who had participated in the pregnancy outcome study. ${ }^{10}$ The same pregnancy for each woman was used as had been used in the previous study. After one case and three controls were excluded on the basis of missing address, or for ethical reasons, 438 subjects remained for further contact.

DATA COLLECTION

A new inquiry took place six years after the first study. A questionnaire was sent to 438 wives of the monitored men to get information on their time to pregnancy and related factors. Those not using contraception during time to pregnancy were asked the following questions: Did you get pregnant during the first menstrual cycle after starting regular unprotected sexual intercourse (when you were trying to get pregnant)? If not, during which menstrual cycle did you get pregnant? The following categories were presented: 2 nd, 3 rd- 4 th, 5-6th, 7-12th, 13-24th, and after the 24th cycle.

The women were asked whether the pregnancy was planned, and the frequency of intercourse. They were asked about the last method of birth control. If they had used an intrauterine device or oral contraceptives they were asked how many months before the study pregnancy they had stopped. There were questions also on breast feeding, and lifestyle factors such as smoking, use of alcohol, coffee or other caffeinated beverages before the pregnancy. Information was requested on the husband's smoking and possible illnesses or some other conditions that could have handicapped his ability to become a father.

The pregnancy history data had been collected in the previous study. ${ }^{10}$ For this study, information on inflammatory diseases, endometriosis, abdominal surgery, medical examination, and treatment for infertility, age at menarche, menstrual regularity, treatment for menstrual irregularity, and the duration of the menstrual cycle was collected by questionnaire.

Information on paternal work history, detailed work tasks, and details of handling the monitored or other solvents during the calendar year in which his wife's pregnancy started had been collected from men in connection with the previous study. ${ }^{10}$ In the questionnaire for this study, additional data on work status, the employer, occupation, and the main work tasks of the wife were collected for the 12 months preceding the pregnancy.
PARTICIPATION AND EXCLUSION CRITERIA After three mailings $316(72 \%)$ wives participated. Thirty four couples were excluded for the following reasons: contraceptive failure in the study pregnancy $(n=12)$, wife had been operated on because of infertility $(n=2)$, wife had endometriosis $(n=2)$ or obstruction of the fallopian tube $(n=1)$, husband's parotitis $(n=1)$, diabetes $(n=1)$, orchitis $(n=1)$, or hydrocele testis as a child $(n=1)$. Thirteen $(4.4 \%)$ of the remaining 295 wives could not determine their time to pregnancy and were therefore excluded. The final study population consisted of 282 couples.

EXPOSURE ASSESSMENT

Paternal exposure to solvents was assessed at the time the attempt at pregnancy began. The classification was based mainly on the self reported work description and solvent use, and on biological measurements of exposure, if available. Biological measurements to complement self reported data on occupational exposure were available for $69 \%$ of the men. For 33 men the measurements had been conducted during the time to pregnancy, and for $161 \mathrm{men}$ from the same job although not during the time to pregnancy. The assessment of exposure used in the previous study ${ }^{10}$ was adopted if the husband had the same job at the beginning of the time to pregnancy of his wife as during 80 days (the estimated period of spermatogenesis) before the beginning of the studied pregnancy $(n=307)$. A new assessment was made by two members of the study group for those men $(n=9)$, whose work tasks had changed during the time to pregnancy. The assessment was made without knowledge of the time to pregnancy.

The likelihood of exposure was categorised as follows: unexposed, if the worker reported no exposure and he was not monitored from that job; potentially exposed, if the work tasks might have involved the use of solvents-for example, gluing - but no clear exposure to solvents was reported and no exposure measurements had been conducted; likely exposed, when the job implied exposure to solvents and there were exposure measurement from that job, or exposure to solvents was reported.

Three exposure levels were used: high or frequent, intermediate or low, and none. The exposure level was classified as high or frequent if the worker handled solvents daily or if the biological exposure measurements indicated clear occupational exposure (above the reference values for the general population). Exposure was defined as intermediate when the solvent was used one to four days a week, and the level of exposure, according the measurements of $\mathrm{FIOH}$, was low. If solvent handling occurred more rarely, the exposure was classified as low. In the main analyses low and intermediate categories were pooled to low or intermediate exposure category including also all potentially exposed workers. In the analyses of individual solvents, intermediate exposure to tetrachloroethylene, trichloroethylene, and 1,1,1trichloroethane was combined within the high exposure category because of small numbers in 
Table 1 Distribution of time to pregnancy by paternal exposure to organic solvents

\begin{tabular}{|c|c|c|c|c|c|c|c|c|}
\hline \multirow{2}{*}{$\begin{array}{l}\text { Level of paternal } \\
\text { exposure to solvent }\end{array}$} & \multicolumn{8}{|c|}{ Time to pregnancy (menstrual cycle (n)) } \\
\hline & 1 & 2 & $3-4$ & $5-6$ & $7-12$ & $13-24$ & $>25$ & Total \\
\hline Unexposed & $25(41.0)$ & $13(21.3)$ & $13(21.3)$ & $4(6.6)$ & $2(3.3)$ & $2(3.3)$ & $2(3.3)$ & 61 \\
\hline Intermediate/ low & $37(46.3)$ & $11(13.8)$ & $15(18.8)$ & $3(3.8)$ & $4(5.0)$ & $7(8.8)$ & $3(3.8)$ & 80 \\
\hline $\mathrm{High} /$ frequent & $52(36.9)$ & $25(17.7)$ & $32(22.7)$ & $11(7.8)$ & $5(3.6)$ & $10(7.1)$ & $6(4.3)$ & 141 \\
\hline Total & $114(40.4)$ & 49 (17.4) & $60(21.3)$ & $18(6.4)$ & $11(3.9)$ & $19(6.7)$ & $11(3.9)$ & 282 \\
\hline
\end{tabular}

Values are $\mathrm{n}(\%)$.

that group. Maternal exposure to solvents was reassessed for 24 wives on the basis of information gathered in the fertility questionnaire.

CONFOUNDING VARIABLES

Recent use of contraceptives was defined if oral contraceptives $(n=70)$ or intrauterine devices $(n=33)$ were discontinued no more than two menstrual cycles before time to pregnancy. The effect of this was considered only in a bivariate model including paternal exposure to organic solvents. We checked that the inclusion of this variable in the model did not have any essential

Table 2 Crude fecundability density ratios (FDR) according to potential confounding factors; proportional hazards modelst

\begin{tabular}{|c|c|c|c|}
\hline Factor & $n(\%)$ & $F D R$ & $95 \% C I$ \\
\hline \multicolumn{4}{|l|}{ Maternal factors: } \\
\hline \multicolumn{4}{|l|}{ Age (y): } \\
\hline $18-20$ & $21(7.4)$ & 0.97 & 0.61 to 1.54 \\
\hline $21-30$ & $213(75.5)$ & 1.00 & reference \\
\hline $31-35$ & $33(11.7)$ & 1.04 & 0.71 to 1.53 \\
\hline $36-40$ & $14(5.0)$ & 1.07 & 0.62 to 1.87 \\
\hline Use of alcohol $>3$ drinks a week & $44(15.6)$ & 0.90 & 0.64 to 1.27 \\
\hline \multicolumn{4}{|l|}{ Smoking: } \\
\hline Ex-smoker or 1-4 cigarettes/day & $76(27.0)$ & 1.21 & 0.91 to 1.61 \\
\hline$\geqslant 5$ Cigarettes/day & $54(19.1)$ & 0.76 & 0.55 to 1.05 \\
\hline Use of coffee $\geqslant 3 \mathrm{cups} /$ day & $207(73.4)$ & 0.86 & 0.65 to 1.13 \\
\hline \multicolumn{4}{|l|}{ Recent contraceptive useł: } \\
\hline IUD & $33(11.7)$ & 0.85 & 0.58 to 1.25 \\
\hline Pill & $70(24.8)$ & 0.90 & 0.68 to 1.20 \\
\hline IUDף & $33(11.7)$ & 0.73 & 0.40 to 1.34 \\
\hline Pillø & $70(24.8)$ & $0.55^{\star}$ & 0.34 to 0.88 \\
\hline Irregular menstruation & $12(4.3)$ & $0.46^{\star}$ & 0.24 to 0.87 \\
\hline \multicolumn{4}{|l|}{ Duration of menstrual cycle (days): } \\
\hline$\leqslant 25$ & $53(18.8)$ & 1.29 & 0.94 to 1.77 \\
\hline$\geqslant 33$ & $11(3.9)$ & 0.57 & 0.31 to 1.06 \\
\hline \multicolumn{4}{|l|}{ Age at menarche $(y)$ : } \\
\hline$<13$ & $102(36.2)$ & 1.06 & 0.81 to 1.38 \\
\hline$\geqslant 15$ & $42(14.9)$ & $1.47^{\star}$ & 1.03 to 2.12 \\
\hline \multicolumn{4}{|c|}{ Previous induced abortion or extrauterine } \\
\hline pregnancy (yes/no) & $18(6.4)$ & 0.90 & 0.55 to 1.48 \\
\hline Previous spontaneous abortion & $40(14.2)$ & 1.21 & 0.85 to 1.71 \\
\hline \multicolumn{4}{|l|}{$\begin{array}{l}\text { Parity: } \\
\text { Pation }\end{array}$} \\
\hline 1 & $128(45.4)$ & 1.12 & 0.86 to 1.47 \\
\hline$\geqslant 2$ & $49(17.4)$ & 1.18 & 0.83 to 1.67 \\
\hline \multicolumn{4}{|c|}{ Year of pregnancy, $1977-9$ as a reference: } \\
\hline $1973-6$ & $77(27.3)$ & 0.98 & 0.71 to 1.35 \\
\hline $1980-3$ & $109(38.7)$ & 0.77 & 0.57 to 1.03 \\
\hline \multicolumn{4}{|l|}{ Pregnancy ended as spontaneous } \\
\hline abortion & $65(23.1)$ & 0.87 & 0.65 to 1.15 \\
\hline Unplanned pregnancy & $37(13.1)$ & 1.30 & 0.90 to 1.87 \\
\hline \multicolumn{4}{|l|}{ Frequency of intercourse: } \\
\hline At most once a week & $93(33.0)$ & 1.18 & 0.90 to 1.57 \\
\hline At least four times a week & $37(13.1)$ & $1.48^{\star}$ & 1.01 to 2.17 \\
\hline Unknown & $9(3.9)$ & 0.89 & 0.42 to 1.89 \\
\hline \multicolumn{4}{|c|}{ Exposure to organic solvents at least one } \\
\hline \multirow{2}{*}{\multicolumn{4}{|c|}{ Paternal factors: }} \\
\hline & & & \\
\hline \multicolumn{4}{|l|}{ Use of alcohol (drinks/week): } \\
\hline $3-9$ & $122(43.3)$ & 0.78 & 0.59 to 1.03 \\
\hline$\geqslant 10$ & $68(24.1)$ & 0.85 & 0.61 to 1.17 \\
\hline \multicolumn{4}{|l|}{ Smoking (cigarettes/day): } \\
\hline $1-4$ & $20(7.1)$ & 1.16 & 0.72 to 1.88 \\
\hline $5-14$ & $71(25.2)$ & 0.96 & 0.72 to 1.28 \\
\hline$\geqslant 15$ & $52(18.4)$ & 0.74 & 0.53 to 1.04 \\
\hline
\end{tabular}

$\star \mathrm{P}<0.05$.

† Adjusted for paternal exposure to organic solvents.

† Has stopped using intrauterine device, pills, or spermicides no more than two months before time to pregnancy started.

I Taken into account only during the first menstrual cycle. effect on the results. In the multivariate analyses, variables indicating the last contraceptive method, if any, were used. A variableunplanned pregnancy-was used, and included women who tried to avoid pregnancy $(n=2)$ or who could not say whether the pregnancy was planned or not $(n=35)$. For caffeine intake, tea was assumed to contain half as much caffeine as coffee on the basis of information obtained from a Finnish coffee roasting house. The amount of caffeine in cocoa (26 users) was assumed to be one tenth of that in coffee. ${ }^{12}$ The year that the studied pregnancy ended was handled as a confounder to control for the potential effect of period. ${ }^{13}$

\section{STATISTICAL ANALYSIS}

Data on time to pregnancy were analysed with the discrete proportional hazards regression ${ }^{14}$ with the SAS LOGISTIC procedure and complementary log log link (SAS). Proportional hazards were assumed during the continuous fertile periods within menstrual cycles. Under this assumption, the discrete proportional hazards model is reasoned, and the outcome variable is interpretable as an incidence density ratio (IDR). As pregnancy is a desired outcome, we use the phrase fecundability density ratio (FDR) in place of IDR of pregnancies. If, for example, an exposed group has a FDR of 0.5 , its sexually active members are half as likely to achieve clinical pregnancy as corresponding unexposed people at any moment during the fertile period in each menstrual cycle.

Time to pregnancy categories $13-24$ cycles and $>24$ cycles were combined to one category to exclude the possible effects of medical treatment for infertility. The $95 \%$ confidence intervals $(95 \% \mathrm{CI})$ were calculated with (SEs) of the variables. Most of the potential confounding factors were analysed as dichotomous, but also multilevel categorical and continuous. Age was forced into the model. The other variables in the final models were selected on the basis of their association with fecundability in the models in which they occurred together with exposure to organic solvents. We checked that the exclusion of other variables from the model had no essential effect on the results. A variable that controlled for missing information was included in the models when necessary. ${ }^{15}$ The value of this variable was set at unity if any of the modelled variables had a missing value, affecting up to 15 subjects in the multivariate models. The missing value of a variable was replaced by zero (not exposed). The complete case analysis $(n=267)$ yielded similar results. Nine of the missing values were related to fre- 
Table 3 Adjusted fecundability density ratio (FDR) by exposure to organic solvents, proportional hazards model $\uparrow$

\begin{tabular}{|c|c|c|}
\hline Exposure & $F D R$ & $95 \% C I$ \\
\hline \multicolumn{3}{|l|}{ Paternal exposure: } \\
\hline \multicolumn{3}{|l|}{ Organic solvents: } \\
\hline Low/intermediate & 0.74 & 0.51 to 1.06 \\
\hline $\mathrm{High} /$ frequent & 0.80 & 0.57 to 1.11 \\
\hline \multicolumn{3}{|l|}{ Smoking (cigarettes/day): } \\
\hline $1-14$ & 1.06 & 0.77 to 1.45 \\
\hline$\geqslant 15$ & 0.76 & 0.53 to 1.10 \\
\hline \multicolumn{3}{|l|}{ Maternal exposure: } \\
\hline \multicolumn{3}{|c|}{ Age at the beginning of TTP $(y)$ : } \\
\hline $18-20$ & 0.88 & 0.54 to 1.45 \\
\hline $31-40$ & 1.21 & 0.88 to 1.65 \\
\hline Age at menarche $\geqslant 15$ & $1.46^{\star}$ & 1.02 to 2.10 \\
\hline \multicolumn{3}{|c|}{ Duration of menstrual cycle (days): } \\
\hline$\leqslant 25$ days & 1.23 & 0.88 to 1.71 \\
\hline$\geqslant 33$ days or irregular & 0.55 & 0.30 to 1.02 \\
\hline \multicolumn{3}{|l|}{ Frequency of intercourse: } \\
\hline At most once a week & 1.18 & 0.89 to 1.57 \\
\hline At least four times a week & $1.70^{\star \star}$ & 1.15 to 2.52 \\
\hline \multicolumn{3}{|l|}{ Smoking (cigarettes/day): } \\
\hline ex-smoker or $1-4$ & 1.27 & 0.93 to 1.73 \\
\hline$\geqslant 5$ & 0.71 & 0.49 to 1.03 \\
\hline \multicolumn{3}{|l|}{ Organic solvents } \\
\hline at least one day a week & 0.55 & 0.25 to 1.22 \\
\hline \multicolumn{3}{|l|}{ Year of pregnancy } \\
\hline $1980-3$ & $0.75^{\star}$ & 0.57 to 0.99 \\
\hline
\end{tabular}

${ }^{\star} \mathrm{P}<0.05 ;{ }^{\star \star} \mathrm{P}<0.01$

†The model includes a variable controlling for missing information.

quency of intercourse. The results were essentially the same in the model where this variable was excluded.

Results

Half of the men (141/282) were assessed to be highly or frequently exposed to organic solvents during the time to pregnancy of the wife, and for $80(28.4 \%)$ the exposure category was low or intermediate (table 1 ). There were no clear systematic differences in the distribution of time to pregnancy between non-exposed and exposed couples. Of the exposed pairs $12 \%$ $(26 / 221)$ had to try for more than a year to get pregnant compared with $7 \%(4 / 61)$ of the nonexposed couples. The unadjusted FDRs were 0.83 (95\% confidence interval (95\% CI) 0.60 to 1.14 ) and 0.88 (95\% CI 0.62 to 1.25$)$ for high or frequent and low exposure, respectively.

The appendix shows the biological measurements for subjects. They are presented only if they were from the job held during time to pregnancy. Only styrene workers often exceeded the national threshold limit value.

Table 4 Adjusted fecundability density ratio (FDR) by exposure to organic solvents for selected subgroups, six proportional hazards modelst

\begin{tabular}{llll}
\hline Exposure to organic solvents & $F D R$ & $95 \%$ CI & Subgroup \\
\hline Low/intermediate & 0.71 & 0.47 to 1.06 & Pregnancies ended in births, \\
High & 0.71 & 0.49 to 1.03 & n=217 \\
Low to high & 0.71 & 0.50 to 1.00 & \\
Low/intermediate & 0.62 & 0.34 to 1.13 & Parity=0, $\mathrm{n}=105$ \\
High & $0.52^{\star}$ & 0.30 to 0.89 & \\
Low/intermediate & 0.73 & 0.44 to 1.22 & Parity $\geqslant 1, \mathrm{n}=177$ \\
High & 0.91 & 0.58 to 1.44 & \\
Low/intermediate & 0.53 & 0.27 to 1.04 & Gravidity $=0, \mathrm{n}=90$ \\
High & $0.36^{\star \star}$ & 0.19 to 0.66 & \\
Low/intermediate & 0.77 & 0.47 to 1.24 & Gravidity $\geqslant 1, \mathrm{n}=192$ \\
High & 0.96 & 0.62 to 1.49 & \\
\hline
\end{tabular}

$\star \mathrm{P}<0.05 ;{ }^{\star \star \star} \mathrm{P}<0.001$.

tAdjusted for short menstrual cycle, long or irregular menstrual cycle, older age at menarche, frequency of intercourse, maternal and paternal smoking, maternal exposure to organic solvents, year of pregnancy, and a variable controlling for missing information.
Table 5 Adjusted fecundability density ratio (FDR) by exposure to organic solvents in selected occupations; proportional hazards models *

\begin{tabular}{llll}
\hline $\begin{array}{l}\text { Occupation and organic } \\
\text { exposure to solvents }\end{array}$ & $n$ & $F D R$ & $95 \%$ CI \\
\hline $\begin{array}{l}\text { Painter: } \\
\quad \text { Low/intermediate }\end{array}$ & 7 & 2.32 & 0.96 to 5.59 \\
$\quad$ High & 57 & 0.82 & 0.55 to 1.22 \\
$\quad \begin{array}{l}\text { Woodworker: } \\
\quad \text { Low/intermediate }\end{array}$ & 2 & 1.12 & 0.24 to 5.12 \\
$\quad$ High & 8 & 0.55 & 0.24 to 1.28 \\
$\begin{array}{l}\text { Plastic worker: } \\
\quad \text { Low/intermediate }\end{array}$ & 12 & 0.98 & 0.50 to 1.92 \\
$\quad$ High & 41 & 0.94 & 0.61 to 1.44 \\
$\quad \begin{array}{l}\text { Metal worker: } \\
\quad \text { Low/intermediate }\end{array}$ & 21 & 0.59 & 0.34 to 1.03 \\
$\quad$ High & 12 & 0.87 & 0.43 to 1.74 \\
$\quad \begin{array}{l}\text { Other worker: } \\
\quad \text { Low/intermediate }\end{array}$ & 37 & 0.73 & 0.47 to 1.14 \\
$\quad$ High & 23 & 0.73 & 0.43 to 1.24 \\
$\quad$
\end{tabular}

^Adjusted for short menstrual cycle, long or irregular menstrual cycle, older age at menarche, frequency of intercourse, maternal age, maternal exposure to organic solvents, and a variable controlling for missing information.

Table 2 shows the distributions and crude FDRs for potential confounding factors. Recent use of oral contraceptives and irregular menstrual cycle were related to reduced fecundability, whereas age $\geqslant 15$ at menarche and frequent intercourses were related to increased fecundability. Adjustment for these had little effect on the effect estimate for organic solvents.

According to the multivariate model in table 3 , there was some evidence that paternal exposure to organic solvents was associated with decreased fecundability, after adjustment for age, age $\geqslant 15$ at menarche, menstrual cycle variables, frequency of intercourse, maternal and paternal smoking, maternal exposure to organic solvents, and year of pregnancy (FDRs

Table 6 Adjusted fecundability density ratio (FDR) by exposure to specific organic solvents, proportional hazards modelst

\begin{tabular}{|c|c|c|c|}
\hline Exposure & $n$ & $F D R$ & $95 \% C I$ \\
\hline \multicolumn{4}{|l|}{ Tetrachloroethylene: } \\
\hline Low/ & 9 & 0.86 & 0.40 to 1.84 \\
\hline Intermediate/high & 8 & 0.68 & 0.30 to 1.53 \\
\hline \multicolumn{4}{|l|}{ Trichloroethylene: } \\
\hline Low & 35 & 0.99 & 0.63 to 1.56 \\
\hline Intermediate/high & 21 & 1.03 & 0.60 to 1.76 \\
\hline \multicolumn{4}{|l|}{ 1,1,1-Trichloroethane: } \\
\hline Low & 15 & 0.98 & 0.53 to 1.82 \\
\hline Intermediate/high & 12 & 0.60 & 0.30 to 1.19 \\
\hline \multicolumn{4}{|l|}{ Toluene: } \\
\hline Low/intermediate & 73 & 0.76 & 0.52 to 1.09 \\
\hline High & 51 & 0.93 & 0.62 to 1.40 \\
\hline \multicolumn{4}{|l|}{ Xylene: } \\
\hline Low/intermediate & 70 & 0.75 & 0.52 to 1.09 \\
\hline High & 51 & 0.91 & 0.61 to 1.36 \\
\hline \multicolumn{4}{|l|}{ Styrene: } \\
\hline Low/intermediate & 46 & 1.10 & 0.73 to 1.66 \\
\hline High & 42 & 0.98 & 0.64 to 1.50 \\
\hline \multicolumn{4}{|c|}{ Aromatic hydrocarbons: } \\
\hline Low/intermediate & 88 & $0.68^{\star}$ & 0.48 to 0.98 \\
\hline High & 96 & 0.98 & 0.69 to 1.38 \\
\hline \multicolumn{4}{|l|}{ Aliphatic hydrocarbon: } \\
\hline Low/intermediate & 78 & 0.85 & 0.59 to 1.22 \\
\hline High & 42 & 0.79 & 0.51 to 1.21 \\
\hline \multicolumn{4}{|c|}{ Halogenated hydrocarbon: } \\
\hline Low/intermediate & 64 & 0.76 & 0.52 to 1.12 \\
\hline High & 13 & 1.17 & 0.61 to 2.24 \\
\hline \multicolumn{4}{|l|}{ Miscellaneous: } \\
\hline Low/intermediate & 61 & 0.98 & 0.67 to 1.43 \\
\hline High & 50 & 0.75 & 0.50 to 1.14 \\
\hline
\end{tabular}

$\star \mathrm{P}<0.05$.

†Adjusted for short menstrual cycle, long or irregular menstrual cycle, older age at menarche, frequency of intercourse, maternal age, maternal exposure to organic solvents, and a variable controlling for missing information. 
$0.80 ; 95 \%$ CI 0.57 to 1.11 for high or frequent exposure and $0.74 ; 95 \%$ CI 0.51 to 1.06 for low or intermediate exposure, respectively).

The results were essentially the same in the analysis of the pregnancies ending in births (table 4). The effects of exposure to solvents on fertility were also examined according to order of pregnancy of the wife. High exposure to organic solvents was significantly associated with decreased fecundability among primigravida and primiparous couples.

Most of the point estimates were under unity in the analyses on exposed subjects by occupations and the type of solvent (tables 5 and 6). The associations were weak and only low or intermediate exposure to aromatic hydrocarbons was significantly related to decreased fecundability. Suggestion of an association was found for exposed woodworkers. A small group of workers exposed to tetrachloroethylene or 1,1,1-trichloroethane seemed also to have lowered fecundability.

\section{Discussion}

There was a suggestion of an association between paternal exposure to organic solvents and decreased fertility in this study. Potential confounders seemed to have only minor or no effect on the results.

ASSESSMENT OF EXPOSURE

Information on work and exposure were collected for the time to pregnancy. The data for exposure assessment were collected in connection with the previous study on spontaneous abortion. This reduced the possibility of recall bias because the study subjects were not aware of the hypothesis to be tested. The exposure assessment was made blindly in relation to the outcome variable. However, nondifferential misclassification of exposure might be present in our study because for $31 \%$ of the men the exposure assessment was based on questionnaire information only.

According to biological monitoring data (appendix) the exposures were low in the final study population. The use of these data for exposure assessment are, however, limited for several reasons. Typically only one component of a mixture of solvents had been measured at a time. No measurements are available for several other solvents-for example, aliphatic hydrocarbons. The biological half lives of the solvent concentrations are short and thus the measurements describe exposure for only the past few days or hours.

RISK ASSOCIATED WITH DIFFERENT SOLVENTS AND OCCUPATIONS

The possible risk could not be attributed to specific solvents or occupations although most of the point estimates for exposure to specific solvents, solvent categories, or for exposure in the most common occupations were below unity. Simultaneous exposure to multiple solvents was common among the study subjects. Therefore, it is necessary to be cautious in interpreting these risk estimates.

In the scientific literature, there is no clear evidence on the possible effects of organic sol- vents on male fertility. The results of the present study on tetrachloroethylene accord with the findings of Eskenazi et $a l^{16}$ showing a slight but non-significant decrease in fecundability. They also found only subtle effects on sperm morphology between dry cleaners and laundry workers whereas sperm concentration, total sperm count, and semen volume were unchanged.

In a Danish study, painters exposed to organic solvents seemed to have an increased risk of infertility compared with agricultural and cement workers. ${ }^{17}$ The results of the present study indicated only slightly decreased fecundability in painters as well as in those with exposure to toluene, xylene, and miscellaneous solvents (including thinners).

Some reports have been published on the effects of solvents on sperm quality. Sperm density was lower in male workers in an electronics industry highly exposed to trichloroethylene compared with a low exposure group. ${ }^{18}$ Surprisingly also prevalence of hyperzoospermia was higher with increasing exposure. In an earlier small study, Rasmussen et $\mathrm{l}^{19}$ found no differences in sperm count and morphology between metal degreasers exposed to trichloroethylene and physicians working at a university. An increase in the number of abnormal sperm heads was found in workers exposed to styrene who produced reinforced plastics compared with patients at the fertility clinic. ${ }^{20}$ The plastics workers had higher percentages of live sperm and motile sperm. Our results did not indicate any association between exposure to trichloroethylene or styrene and fertility.

It is difficult to assess the findings of studies on human sperm in terms of the ability to conceive children, although there is evidence that the motile sperm count is related to fecundability. ${ }^{21}$ However, decreased sperm count and semen quality are only a few of many indicators of decreased fertility. Many other mechanisms (non-genetic, genetic, and epigenetic) are proposed for male mediated effects on reproductive toxicity. ${ }^{22} 23$

RESPONSE RATE AND RECALL

The participation rate was moderate. Based on information from the study on spontaneous abortion we had the opportunity to compare participation according to some variables including paternal exposure to solvents before conception. The wives of unexposed men were more compliant (response rate $69 / 86=80 \%$ ) than the wives of exposed men (247/352 = $70 \%)$. Women with at least two previous births were less willing to participate (response rate $59 / 91=65 \%$ ) compared with primigravida $(115 / 152=76 \%)$ and women with one previous birth $(142 / 194=73 \%)$. The response rates were similar among the cases of spontaneous abortion $(77 / 109=71 \%)$ and the controls $(239 / 329=73 \%)$. The crude odds ratios (ORs) of spontaneous abortion were lower among the respondents (ORs 1.9 and 1.1 for high or frequent and low or intermediate exposure, respectively) than those in the total population (ORs 3.1 and 2.2). Also, the response rates were $79 \%$ among the cases and $73 \%$ among the 
controls in the original study. ${ }^{10}$ Thus, possible effects of response bias cannot be ruled out.

Data on time to pregnancy were collected eight to 18 years after the pregnancies. Nearly all of the wives were able to state the duration of their time to pregnancy within given categories. The possibility of recall bias cannot, however, totally be ruled out. The direction of the potential response and recall biases cannot be assessed.

STUDY DESIGN: PREGNANCY OUTCOME

Our study is an extension to the case-referent study on spontaneous abortion. Therefore, the proportion of pregnancies ending in spontaneous abortion was as high as $23 \%$. Pregnancies ending in spontaneous abortion tend to have longer times to pregnancy than those ending in births. ${ }^{24-26}$ Also, the data on time to pregnancy might not be as accurate for spontaneous abortions as for births. Thus, the FDR for exposure to solvents found in the whole study population might be biased. However, the association was only slightly stronger among the pregnancies ending in births.

STUDY DESIGN: PREGNANCY ORDER

The FDRs for high or frequent paternal exposure to solvents varied by pregnancy order of the wife. In the stratified analyses among primigravida or primiparous wives high exposure was significantly associated with decreased fertility whereas exposure was not related to fecundability among wives who had previous pregnancies.

It is unlikely that the true FDRs for exposure differ according to gravidity or parity. Rather, this finding might be related to chance or to some selection process. Significant associations might be found in subgroups of the study population which have nothing to do with causality due to multiple comparisons. ${ }^{27}$ Caution has been advised in interpreting findings in subgroups in case they are not based on genetic markers of susceptibility. ${ }^{28}$

If the results of first pregnancies differ from the overall measure, selection bias may be the explanation. ${ }^{29}$ However, it is unlikely that the monitored men considered exposure to solvents harmful to paternal reproduction and selected their job according to past pregnancy histories.

As a retrospective study, comprised of pregnancies which ended within an 11 year cross section, ours is susceptible to selection bias. If the exposure is associated with sterility or long times to pregnancy, a bias towards unity will follow. ${ }^{6}$ Couples who are sterile are not included. Particularly exposed older couples, who had pregnancies before the study period, might be underrepresented in our study, because for a subgroup of them the fertile period of the marital life only partly overlaps with the study period. The difference in FDRs according to pregnancy order might suggest that this kind of selection process is present in our data.

\section{Conclusions}

We have previously found an association between paternal exposure to organic solvents and increased risk of spontaneous abortion. The present study provides limited support for the hypothesis that paternal exposure to organic solvents is associated with decreased fertility. In general, the associations were weak and the possible risk could not be attributed to specific solvents or occupations. Further studies with careful design are warranted.

The study was supported by a grant from the Finnish Work Environment Fund. We thank Paula Karvinen and Lea Aalto for assisting with the data collection and coding, Lars Nylund for linguistic revision of the Swedish questionnaire, and Simo Virtanen for linguistic revision of the manuscript.

\section{Appendix}

Biological measurements of organic solvents among men holding the same job during time to pregnancy and measurements

\begin{tabular}{|c|c|c|c|c|c|c|c|c|}
\hline \multirow{2}{*}{$\begin{array}{l}\text { Exposure, and } \\
\text { measurement }\end{array}$} & \multirow{2}{*}{$\begin{array}{l}\text { Level of } \\
\text { exposure }\end{array}$} & \multirow[b]{2}{*}{$n$} & \multirow{2}{*}{$\begin{array}{l}\text { Arithmetic } \\
\text { mean }\end{array}$} & \multirow[b]{2}{*}{$S D$} & \multirow[b]{2}{*}{ Median } & \multicolumn{2}{|l|}{ Result $>$ FRV of } & \multirow{2}{*}{$\begin{array}{l}\text { FRV of } \\
\text { exposed/ } \\
\text { unexposed }\end{array}$} \\
\hline & & & & & & Unexposed (\%) & Exposed (\%) & \\
\hline Styrene, ${ }^{\star}$ & $\mathrm{H}$ & 46 & 3.58 & 3.75 & 2.49 & 69.6 & 17.4 & $7.0 /$ \\
\hline U-ManA (mmol/l) & $\mathrm{L} / \mathrm{I}$ & 21 & 1.52 & 2.73 & 0.23 & 33.3 & 4.8 & $<1.0$ \\
\hline Toluene, $\dagger$ & $\mathrm{H}$ & 24 & 0.33 & 0.33 & 0.30 & 25.0 & 0 & $2.0 /$ \\
\hline B-Tol, $\mu \mathrm{mol} / 1$ & $\mathrm{~L} / \mathrm{I}$ & 5 & 0.38 & 0.65 & 0 & 20.0 & 0 & $<0.5$ \\
\hline Xylene, ${ }^{\star}$ & $\mathrm{H}$ & 11 & 0.45 & 0.45 & 0.36 & 72.7 & 0 & $10.0 /$ \\
\hline U-MeHipA (mmol/l) & $\mathrm{L} / \mathrm{I}$ & 2 & 0 & 0 & 0 & 0 & 0 & $<0.1$ \\
\hline Trichloroethylene $e^{\star}$ & $\mathrm{H}$ & 13 & 45 & 42 & 31 & 23.1 & 0 & $360 /$ \\
\hline U-TCA $(\mu \mathrm{mol} / \mathrm{l})$ & $\mathrm{L} / \mathrm{I}$ & 22 & 41 & 88 & 15 & 13.6 & 4.5 & $<50$ \\
\hline Tetrachloroethylene, $\dagger$ & $\mathrm{H}$ & 1 & 0.50 & - & 0.50 & 100 & 0 & $2.5 /$ \\
\hline B-Per $(\mu \mathrm{mol} / \mathrm{l})$ & $\mathrm{L} / \mathrm{I}$ & 1 & 0.60 & - & 0.60 & 100 & 0 & $<0.1$ \\
\hline $1,1,1$-Tri-chloroethane, $\dagger$ & $\mathrm{H}$ & 1 & 0 & - & 0 & 0 & 0 & $1.2 /$ \\
\hline B-TC $(\mu \mathrm{mol} / 1)$ & $\mathrm{L} / \mathrm{I}$ & 1 & 0.06 & - & 0.06 & 0 & 0 & $<0.1$ \\
\hline
\end{tabular}

${ }^{\star}$ Measurements with urine specific gravity $<1.008$ excluded.

†Only morning samples included.

$\mathrm{H}=$ high; $\mathrm{L} / \mathrm{I}=$ low or intermediate;

FRV $=$ Finnish reference value in 1985, FRV of exposed men is the national threshold limit value. 
1 Nylen P, Ebendal T, Eriksdotter-Nilsson M, Hansson T, Henschen A, Johnson A-C, et al. Testicular atrophy and loss of nerve growth factor-immunoreactive germ cell line in rats exposed to $n$-hexane and a protective effect of simultaneous exposure to toluene or xylene. Arch Toxicol 1989;63:296

2 Yamada K. Influence of lacquer thinner and some organic solvents on reproductive and accessory reproductive organs in the male rat. Biol Pharm Bull 1993;16:425-7.

3 Henderson J, Baker HWG, Hanna PJ. Occupation-related male infertility: a review. Clinical Reproduction and Fertility 1986;4:87-106

4 Lähdetie J. Occupation and exposure related studies on human sperm. f Occup Environ Med 1995;37:922-30.

5 Lindbohm M-L. Effects of parental exposure to solvents on pregnancy outcome. f Occup Environ Med 1995;37:908preg.

6 Baird DD, Wilcox AJ, Weinberg CR. Use of time to pregnancy to study environmental exposures. $A m$ F pregnancy to study environ

7 Joffe M, Villard L, Li Z, Plowman R, Vessey M. Long term recall of time-to-pregnancy. Fertil Steril 1993;60:99-104.

8 Eskenazi B, Fenster L, Hudes M, Wyrobeck AJ, Katz DF, Gerson J, Rempel DM. A study on the effect of perchloroethylene exposure on the reproductive outcomes of wives of dry cleaning workers. Am $\mathcal{F}$ Ind $\mathrm{Med}$ 1991;20:593-600.

9 Correa A, Gray D, Cohen R, Rothman N, Shah F, Seacat H, Corn M. Ethylene glycol ethers and risk of spontaneous abortion and subfecundity. Am F Epidemiol 1996;143:70717.

10 Taskinen H, Anttila A, Lindbohm M-L, Sallmén M, Hemminki K. Spontaneous abortions and congenital malformations among the wives of men occupationally 1989;15:345-52.

11 Lindbohm M-L, Hemminki K. Nationwide data base on medically diagnosed spontaneous abortions in Finland. Int medically diagnosed spontan

12 Dlugosz L, Bracken MB. Reproductive effects of caffeine: a review and theoretical analysis. Epidemiol Rev 1992;14:83100.

13 Pajarinen J, Laippala P, Penttilä A, Karhunen PJ. Incidence of disorders of spermatogenesis in middle aged Finnish men, 1981-91: two necropsy series. BMF 1997;314:13-8.
14 Kalbfleisch JD, Prentice RL. The statistical analysis of failuretime data. New York: Wiley, 1980.

5 Miettinen OS. Theoretical epidemiology. New York: John Wiley, 1985

16 Eskenazi B, Wyrobeck AJ, Fenster L, Katz DF, Sadler M, Lee $\mathrm{J}$, et al. A study on the effect of perchloroethylene exposure on semen quality in dry cleaning workers. $A m \mathcal{F}$ Ind Med 1991;20:575-91.

17 Bjerrehus T, Detlefsen GU. Infertilitet hos danske malere udsat for organiske opløsningsmidler. Ugersk Lager 1986; 18:1105-6.

18 Chia SE, Ong CN, Tsakok MFH, Ho A. Semen parameters in workers exposed to trichloroethylene. Reprod Toxicol 1996;10:295-9.

19 Rasmusen K, Sabroe S, Wohlert M, Ingerslev HJ, Kappel B, Nielsen J. A genotoxic study of metal workers exposed to trichloroethylene. Sperm parameters and chromosome aberrations in lymphocytes. Int Arch Occup Environ Health 1988;60:419-23.

20 Jelnes JE. Semen quality in workers producing reinforced plastic. Reprod Toxicol 1988;2:209-12.

21 Steiberger E, Rodriguez-Rigau LJ. The infertile couple. $\mathcal{F}$ Androl 1983;4:111-8.

22 Olshan AF, Faustman EM. Male-mediated developmental toxicity. Annu Rev Publ Health 1993;14:159-81.

23 Wyrobeck AJ. Methods and concepts in detecting abnormal reproductive outcomes of parental origin. Reprod Toxicol 1993;7:3-16.

24 Schaumburg I, Boldsen J. Waiting time to pregnancy and pregnancy outcome among Danish workers in the textile, clothing, and footwear industries. Scand f Soc Med 1992;20:110-4.

$25 \mathrm{Joffe} \mathrm{M}, \mathrm{Li} \mathrm{Z}$. Association of time to pregnancy and the outcome of pregnancy. Fertil Steril 1994;2:71-5.

26 Sallmén M, Lindbohm M-L, Kyyrönen P, Nykyri E, Anttila A, Taskinen $\mathrm{H}$, Hemminki $\mathrm{K}$. Reduced fertility among women exposed to organic solvents. Am 7 Ind Med 1995;27:699-713.

27 Mills JL. Data torturing. N Engl f Med 1993;329:1196-9.

28 Hatch $M$. What can we infer from findings in subgroups? Epidemiology 1995;6:473-5.

29 Olsen J. Options in making use of pregnancy history in planning and analyzing studies of reproductive failure. $\mathcal{f}$ Epidemiol Community Health 1994;48:171-4.

\section{Correspondence and editorials}

Occupational and Environmental Medicine welcomes correspondence relating to any of the material appearing in the journal. Results from preliminary or small scale studies may also be published in the correspondence column if this seems appropriate. Letters should be not more than 500 words in length and contain a minimum of references. Tables and figures should be kept to an absolute minimum.
Letters are accepted on the understanding that they be subject to editorial revision and shortening.

The journal also publishes editorials which are normally specially commissioned. The Editor welcomes suggestions regarding suitable topics; those wishing to submit an editorial, however, should do so only after discussion with the Editor. 